\title{
Identification and characterization of a novel linear epitope in the spike protein of the porcine epidemic diarrhea virus
}

\author{
L. GONG, Y. GONG, Y. LIN, J. QIN, Y. LIU, X. QIAN, C. XUE, Y. CAO*
}

State Key Laboratory of Biocontrol, School of Life Sciences, Sun Yat-sen University, Guangzhou, P. R. China

Received April 3, 2018; revised May 31, 2018; accepted January 31, 2019

\begin{abstract}
Summary. - The main immunogenic protein of the porcine epidemic diarrhea virus (PEDV) is the spike protein (S protein), which plays an important role in receptor binding, membrane fusion, and viral invasion of the host. In this paper, the linear epitope of the 3F10 non-neutralizing monoclonal antibody that was previously prepared in our laboratory was identified. The expression of truncated forms of the S protein for $3 \mathrm{~F} 10$ reaction studies proved that the epitope was located between amino acids (aa) 674 and 791 . To further locate the core aa of the 3 F10 epitope, 12 random peptide libraries were used, and the result showed that the key aa located at aa $685-688$ of the S protein (LLAF) were recognized by 3F10. Homology analysis of the regions corresponding to 20 typical strains of different PEDV subtypes showed that the epitope is highly conserved. Identifying the epitope recognized by an antibody helps to improve our understanding of the structure and function of the antigen.
\end{abstract}

Keywords: spike protein; linear epitope; homology analysis

\section{Introduction}

Porcine epidemic diarrhea (PED), which is caused by porcine epidemic diarrhea virus (PEDV), is a severe porcine infectious disease that is mainly characterized by severe watery diarrhea, vomiting, dehydration and even death in unweaned piglets (Song et al., 2012). Clinically, unweaned piglets less than 10 days old are the most susceptible and have the most severe clinical manifestations (Jung et al., 2015). PED is one of the most widespread porcine diseases in the world; it was reported for the first time in the UK and Belgium in 1978 and later spread to many countries in Asia and Europe (Oldham, 1972; Song et al., 2012). PED broke out for the first time in America in 2013, causing substantial economic losses for the global pig husbandry industry (Mole, 2013). The incidence of diarrhea in pig farms is currently high, the morbidity is increasingly com-

*Corresponding author. E-mail: caoych@mail.sysu.edu.cn; phone: +86-20-39332934.

Abbreviations: $\mathrm{PED}=$ porcine epidemic diarrhea; $\mathrm{PEDV}=\mathrm{PED}$ virus; $\mathrm{mAbs}=$ monoclonal antibodies; IFA $=$ indirect immunofluorescence assay plicated, and mixed infections are reported frequently. Thus, the clinical diagnosis of PEDV is attracting more attention among researchers.

PEDV belongs to the genus Alphacoronavirus (the family Coronaviridae) and contains positive-strand RNA with a cap at the 5 ' end and a poly (A) tail at the 3 ' end. The major structural proteins of PEDV include the spike protein (S), membrane protein $(\mathrm{M})$, nucleocapsid protein $(\mathrm{N})$, and small envelope protein (E) (Lee, 2015). The main immunogenic protein of PEDV is the $S$ protein, which is located on the surface of the virus and is the main envelope protein (Oh et al., 2014). The S protein plays an important role in receptor binding, membrane fusion, and viral invasion into the host and contains the main antigenic epitopes that induce the host to produce neutralizing antibodies (Li et al., 2016). Based on the Flynn-like protease cleavage site, the $S$ protein is divided into two parts, S1 and S2, of which S1 is the head and S2 is the neck (Wang et al., 2016a). Recent studies showed that the S1 protein contains four linear epitopes, 744-759, 756-771, 748-755 and 764-771 (Sun et al., 2008; Cao et al., 2015). In addition, two conformational epitope regions (499-638 and 636-789) were identified that can induce the production of neutralizing antibodies (Chang et al., 2002; Sun et al., 2007). S2 protein region $1368-1374$ is also a neutralizing epitope 
(Cruz et al., 2006). Neutralizing antibody production has a strong protective effect against reinfection with PEDV, so the $S$ protein is the most important target protein in the development of a genetically engineered PEDV vaccine.

However, the antibodies against immunodominant epitopes secreted by most B cells do not have neutralizing activity (Burton, 2002). Extensive evidence shows that nonneutralizing antibodies play a crucial role in reducing the viral load and in providing full or partial protection (Howell et al., 2017; Mayr et al., 2017). An improved understanding of non-neutralizing antibodies will contribute to the development of new vaccine development strategies, and the right combination of different antibodies can exhibit a good synergistic effect.

In our laboratory, 10 monoclonal antibodies (mAbs) against PEDV were obtained by the hybridoma technique, and the 3F10 antibody was reacting with the S protein (amino acids (aa) 21-791) expressed by baculovirus (Gong et al., 2018). In this study, the 3F10 mAb was selected to identify and analyze the antigenic epitopes of the viral S protein. This investigation helps to provide the foundation for further studies of the function of non-neutralizing antibodies and the establishment of specific diagnostic methods.

\section{Materials and Methods}

Cells, viruses and reagents. African green monkey kidney (Vero) cells were cultured in Dulbecco's modified Eagle's medium (DMEM) containing $10 \%$ serum at $37^{\circ} \mathrm{C}$ and $5 \% \mathrm{CO}_{2}$. The PEDV strains GDS01 and GDS03 were isolated and preserved in our own experiments. The virus was proliferated on Vero cells with a trypsin concentration of $10 \mu \mathrm{g} / \mathrm{ml}$. mAbs and polyclonal antibodies were prepared in our laboratory. Twelve random peptide libraries were purchased from New England BioLabs (NEB).

Preliminary epitope localization analysis. A previous study showed that the 3F10 antibody could react with the $S$ protein 1-954 aa fragment. According to the truncation approach reported by Hao's research (Hao et al., 2017), S protein (21-954 aa) was divided into 7 segments, which were cloned into the PBCX vector and named SP1 (21-247 aa), SP2 (499-790 aa), SP3 (248-498 aa), SP4 (791-954 aa), SP5 (143-344 aa), SP6 (437-667 aa) and SP7 (674-899 aa). The recombinant plasmids were transformed into BL21, and the different segments were expressed by means of isopropyl $\beta$-D-1-thiogalactopyranoside (IPTG) induction and purified by a Ni column. Seven purified fusion proteins were detected on western blots (WBs) by the $3 \mathrm{~F} 10 \mathrm{mAb}$.

B cell epitope prediction. A bioinformatics website (http:// imed.med.ucm.es/Tools/antigenic.pl) was used to predict the B cell epitopes of the PEDV S protein (674-791 aa). The system is based on the algorithm developed by Kolaskar and Tongaonkar, with a $75 \%$ accuracy rate over years of application (Kolaskar and Tongaonkar, 1990).
Phage screening and enrichment. To accurately pinpoint key aa of the $3 \mathrm{~F} 10$ epitope, the $3 \mathrm{~F} 10 \mathrm{mAb}$ was subjected to 5 rounds of biopanning according to the instruction manual for the 12 phage display peptides from NEB. The concentration of the target protein used for coating was decreased to $20 \mu \mathrm{g}, 10 \mu \mathrm{g}, 5 \mu \mathrm{g}, 2 \mu \mathrm{g}$, and $1 \mu \mathrm{g}$ per round, while the concentration of Tris-buffered saline with Tween 20 (TBST) was increased to $0.1 \%, 0.2 \%, 0.3 \%, 0.4 \%$, and $0.5 \%$ per round. The purified $\mathrm{mAb}$ was diluted in coating liquid (0.1 mol/ $\left./ \mathrm{NaHCO}_{3}, \mathrm{pH} 8.6\right)$; then, $100 \mu \mathrm{l}$ of coating liquid was added to microtiter wells and incubated overnight at $4^{\circ} \mathrm{C}$. The coating liquid was removed on the second day, and $5 \%$ bovine serum albumin (BSA) was added at $4^{\circ} \mathrm{C}$ for $1 \mathrm{~h}$. The blocking liquid was removed, and the sample was washed with $0.1 \%$ TBST. Then, $10^{11}$ plaque-forming units (PFU)/100 $\mu$ l of the original phage library was added to each well, and the samples were rocked gently for $1 \mathrm{~h}$ at room temperature. Uncombined phage was removed, and the samples were washed 10 times with $0.1 \%$ TBST. Then, $100 \mu \mathrm{l}$ of eluent buffer ( $0.2 \mathrm{~mol} / \mathrm{l}$ glycine- $\mathrm{HCl}, \mathrm{pH} 2.2,1 \mathrm{mg} / \mathrm{ml} \mathrm{BSA})$ was added, and the samples were rocked for $15 \mathrm{~min}$ at room temperature. A total of $15 \mu \mathrm{l}$ of $1 \mathrm{~mol} / \mathrm{l}$ Tris- $\mathrm{HCl}, \mathrm{pH}$ 9.1, was added. The eluate was used for phage amplification and titering. The eluate was added to $20 \mathrm{ml}$ of ER2738 culture, which was particularly well-suited for M13 propagation. (the thallus was in the early-log phase, OD600 $0.01-0.05$ ) with shaking for $4.5 \mathrm{~h}$ at $37^{\circ} \mathrm{C}$. The culture was moved into a fresh tube and centrifuged for $10 \mathrm{~min}$ at $12,000 \mathrm{xg}$ at $4^{\circ} \mathrm{C}$. The supernatant was moved to a fresh tube and recentrifuged. Then, $80 \%$ of the upper supernatant was transferred into a fresh tube, and a $1 / 6$ volume of polyethylene glycol (PEG)/ $\mathrm{NaCl}$ was added. The phage was subjected to overnight sedimentation at $4^{\circ} \mathrm{C}$. The PEG was centrifuged to absorb residual supernatant. The sample was suspended in $1 \mathrm{ml}$ of Tris-buffered saline (TBS) and centrifuged at $12,000 \mathrm{x} \mathrm{g}$ for $5 \mathrm{~min}$ at $4^{\circ} \mathrm{C}$. Then, the supernatant was transferred into another fresh tube. A 1/6 volume of $\mathrm{PEG} / \mathrm{NaCl}$ was added, and the sample was incubated for 15-60 min and centrifuged at $12,000 \mathrm{xg}$ for $10 \mathrm{~min}$ at $4^{\circ} \mathrm{C}$. The supernatant was then discarded. The precipitate was suspended in $200 \mu \mathrm{l}$ of TBS and centrifuged for $1 \mathrm{~min}$. The supernatant was transferred into a fresh tube and represented the amplified eluate. A plate was coated to be used in next round of panning.

Plaque amplification and sequencing. An overnight culture of ER2738 was diluted and inoculated into Luria-Bertani (LB) medium. Plates with less than 100 blue plaques in the fifth round were removed to determine the titer of the eluate. Blue bacteriophage plaques on the plate were selected with a sterilized toothpick and amplified. A total of $200 \mu \mathrm{l}$ of PEG/ $\mathrm{NaCl}$ was added, and the sample was mixed and incubated for $10 \mathrm{~min}$ at room temperature. The tube was subjected to centrifugation at $12,000 \mathrm{x} \mathrm{g}$ for $10 \mathrm{~min}$ at $4^{\circ} \mathrm{C}$. The supernatant was discarded. The precipitate was suspended in $100 \mu \mathrm{l}$ of iodide buffer solution, and $250 \mu \mathrm{l}$ of ethanol was added to the solution. The solution was incubated for $20 \mathrm{~min}$ at room temperature, and single-stranded phage DNA was precipitated. The solution was subjected to centrifugation at $12,000 \mathrm{x}$ g for $10 \mathrm{~min}$ at $4^{\circ} \mathrm{C}$. The supernatant was discarded. Then, $0.5 \mathrm{ml}$ of $70 \%$ ethanol 


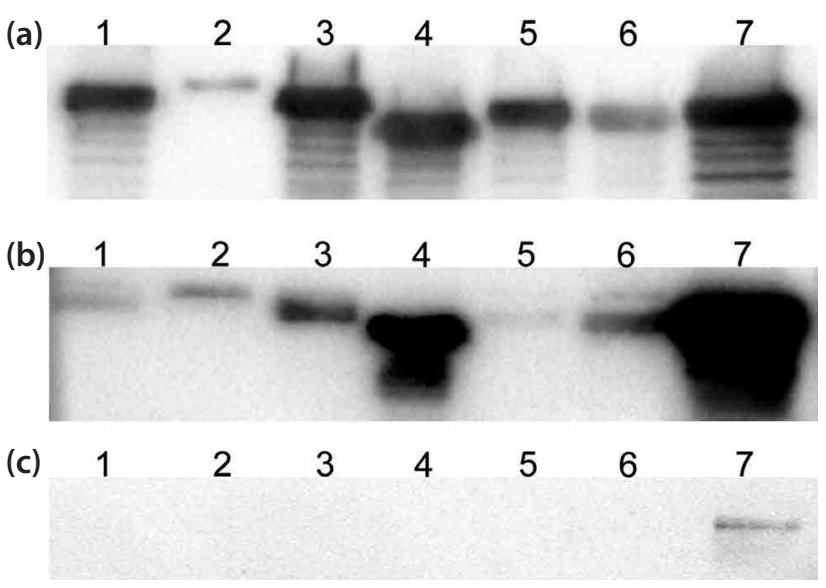

Fig. 1

Western blotting analysis of recombinant proteins with $\mathrm{mAb} 3 \mathrm{~F} 10$ (a) His-labeled antibody; (b) anti-PEDV polyclonal antibody; and (c):3F10 mAb. Lanes 1-7 represent SP1-SP7, respectively.

(pre-cooled at $-20^{\circ} \mathrm{C}$ ) was used to wash the precipitate. The precipitate was then subjected to short vacuum drying. The precipitate was re-suspended in $30 \mu \mathrm{l}$ of $\mathrm{ddH}_{2} \mathrm{O} .96$ gIII sequencing primer (5'-Ho CCCTCATAGTTAGCGTAACG-3') was applied to a 96-well plate for automatic sequencing.

Affinity test. The sequenced phage was subjected to amplification and titering. Then, $10 \mu \mathrm{g}$ of $\mathrm{mAb}$ was used to coat each well of an ELISA plate overnight at $4^{\circ} \mathrm{C}$; the coating solution was discarded on the second day. The plate was washed 3 times with $0.05 \%$ TBST, and phage that had been diluted tenfold continuously was added to each well for $1 \mathrm{~h}$ at room temperature. Then, $0.05 \%$ TBST was used to remove uncombined phage after the solution was discarded. An anti-m13 phage antibody (diluted 1:1000) was added after the plate had been washed 3 times, and the plate was incubated for $1 \mathrm{~h}$ at $37^{\circ} \mathrm{C}$ and then washed. Then, a horseradish peroxidase (HRP)labeled goat anti-mouse IgG (diluted 1:5,000) was added for $1 \mathrm{~h}$ at $37^{\circ} \mathrm{C}$, and $0.05 \%$ TBST was used to wash the plate 3 times. The 3,3',5,5'-tetramethylbenzidine (TMB) colorimetric liquid substrate was used to develop the results. The OD value at $450 \mathrm{~nm}$ was read by a Biotek elx 800 .

ELISA reaction of polypeptides with $3 F 10$. Thirty-six base sequences could be inferred from the sequencing results. Those sequences were translated into 12 aa and compared with protein $S$ (674-791 aa). Twelve deduced peptides were obtained by chemical synthesis with a purity of $95 \%$ from the BGI company. Then, $100 \mu \mathrm{g} / 100 \mu \mathrm{l}$ of polypeptide was incubated in an ELISA plate overnight at $4^{\circ} \mathrm{C}$, and $5 \%$ BSA was used for blocking. The $3 \mathrm{~F} 10$ antibody was added at a 1:1000 dilution and incubated for $1 \mathrm{~h}$ at room temperature. The HRP-labeled goat anti-mouse IgG secondary antibody (1:4,000 dilution) was used for ELISA detection. The values were read at an OD of $450 \mathrm{~nm}$. Meanwhile, 12 random peptides were set as the negative control. Each well had 3 duplicates, which were used for error calculation.

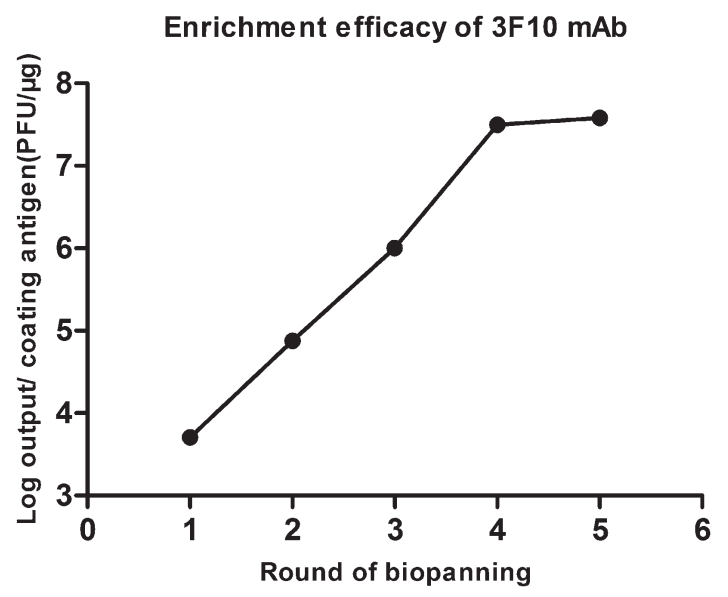

Fig. 2

Enrichment efficacy of the $3 \mathrm{~F} 10 \mathrm{mAb}$

The log output of the selected phage per unit mass of 3F10 is shown on the $\mathrm{y}$-axis. The round of biopanning is shown on the $\mathrm{x}$-axis.

3F10 antigenic epitope analysis. The key aa sequences of the antigenic epitope of 3F10 that were obtained through analysis were subjected to specificity comparison and analysis with 9 representative strains of prevalent PEDV strains and 11 representative strains of classic PEDV strains.

Cross-reaction between $3 F 10$ and classical virus strains - indirect immunofluorescence assay (IFA). Reactions between 3F10 and the GDS03 strain were evaluated by an indirect immunofluorescence assay (IFA). A monolayer of Vero cells was grown to $90 \%$ to $100 \%$ confluence, washed with phosphate-buffered saline (PBS) three times and then inoculated with GDS03 at 100 folds of tissue culture infective dose (TCID) ${ }_{50}$ with $10 \mu \mathrm{g} / \mathrm{ml}$ tyrosine. Approximately $24 \mathrm{~h}$ to $36 \mathrm{~h}$ after infection, $4 \%$ paraformaldehyde was used to fix the cells for $15 \mathrm{~min}$, and the cells were washed with PBS three times after the cells exhibited evident pathological changes. For cell permeabilization, $0.5 \%$ Triton X-100 was added for $15 \mathrm{~min}$, and the cells were washed with PBS 3 times. A blocking solution containing $3 \% \mathrm{BSA}$ was added for $1 \mathrm{~h}$ at $37^{\circ} \mathrm{C}$ and then discarded. The diluted $\mathrm{mAb}(1: 1000)$ with $1 \% \mathrm{BSA}$ was added for $1 \mathrm{~h}$ at $37^{\circ} \mathrm{C}$. The primary antibody solution was absorbed and discarded, and the samples were washed with PBS three times for $5 \mathrm{~min}$ each time. The diluted secondary antibody (1:500) containing 1\% BSA was added for $1 \mathrm{~h}$ at $37^{\circ} \mathrm{C}$. The secondary antibody solution was absorbed and discarded, and the samples were washed with PBS three times for 5 min each time. A Nikon fluorescence microscope was used for observation.

\section{Results}

\section{Analysis of preliminary positions of the antigenic epitope}

To accurately position the functional domain of the 3F10 antigenic epitope, protein S (21-794 aa) was divided into 
7 peptide fragments for prokaryotic expression. The 3F10 $\mathrm{mAb}$, a His-labeled antibody and an anti-PEDV polyclonal antibody were used for SDS-PAGE to identify the 7 polypeptides. The result shows that 3F10 can react only with SP7. There was an overlapping area between SP4 (791-954 aa) and SP7 (674-899 aa). 3F10 could react with SP7 rather than SP4, which indicates that the identified region of $3 \mathrm{~F} 10$ was aa 674-791 (Fig. 1). In terms of the results obtained for the Hislabeled antibody and the polyclonal antibody, the epitope identified by SP7 may be the immunodominant epitope.

\section{Phage screening and enrichment}

To identify key aa of the 3F10 mAb epitope, the purified $3 \mathrm{~F} 10 \mathrm{mAb}$ was used as a target molecule to conduct 5 rounds of phage screening. The $\mathrm{mAb}$ quantity and the input and output of phage were calculated in each round of the screening process, and the output/input ratio per microgram of $\mathrm{mAb}$ was compared for each round. As shown in Fig. 2, if the coating quantity of 3F10 gradually decreased with unchanged input, the phage absorbed by the $\mathrm{mAb}$ per unit of mass exhibited a trend toward a progressive increase; thus, the phage was obviously enriched after 5 rounds of screening.

\section{Affinity determination and sequence alignment}

The elution product screened in the fifth round was titered, and plates with less than 100 blue colonies were selected. Nineteen blue colonies of monoclonal phages were selected for amplification and sequencing. The result shows that the 19 monoclonal phages are divided into two categories. The peptide fragment of Phage1 (Ph1) was SFM SHAGIFKSY, and the peptide fragment of Phage2 (Ph2) was LLAFMGLHKGRW. Ph1 and Ph2 had high affinity for 3F10 through the indirect ELISA method, while wild-type phage did not react with 3F10 (Fig. 3). This finding showed that the screened phage was a positive phage clone that targeted $\mathrm{mAb}$ 3 F10 through a specific reaction to a protein encoded by the phage. Twelve peptides from $\mathrm{Ph} 1$ and $\mathrm{Ph} 2$ were subjected

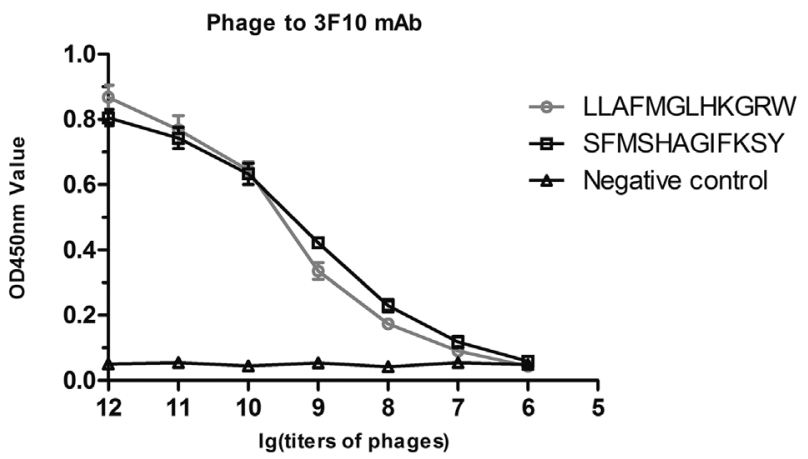

Fig. 3

Binding analysis of the selected phage and 3F10 by indirect ELISA A phage containing LLAFMGLHKGRW, a phage containing SFM SHAGIFKSY and a wild-type phage were incubated with the $3 \mathrm{~F} 10 \mathrm{mAb}$ to assess their binding affinities. The OD450 values of the individual phages are shown on the $y$-axis. The log values of the phage titers are shown on the $\mathrm{x}$-axis.

to multiple sequence alignment with $\mathrm{S}$ protein $674-791$ aa, which indicated that aa 683-686 of LLAF in $\mathrm{Ph} 2$ and the S protein had high similarity (Fig. 4). The data showed that peptide fragment LLAF of Ph2 was the virtual epitope identified by $3 \mathrm{~F} 10$.

\section{Association between the polypeptide and the 3F10 mAb}

The methods described by Kolaskar and Tongaonkar (1990) were used to predict the B cell epitopes of the S protein 674-791 aa fragment. The result showed that the peptide fragment may contain three B cell epitopes. The first peptide fragment (7-14 aa, SGQLLAFK) completely includes the key aa from Ph2 (Table 1). As the peptide fragment presented on the phage could not represent the true epitope of $3 F 10$ in the $S$ protein, $S$ protein fragment pep LLAF $_{\text {L }}$ $\left({ }_{680}\right.$ SDSGQL LAFKNV $\left._{691}\right)$, which included LLAF; S protein fragment pep DLLAF $_{680}$ SDSGQHTTPKNV $\left.{ }_{691}\right)$, which was a random replacement of LLAF; and the unrelated peptide

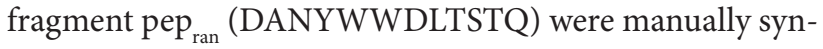

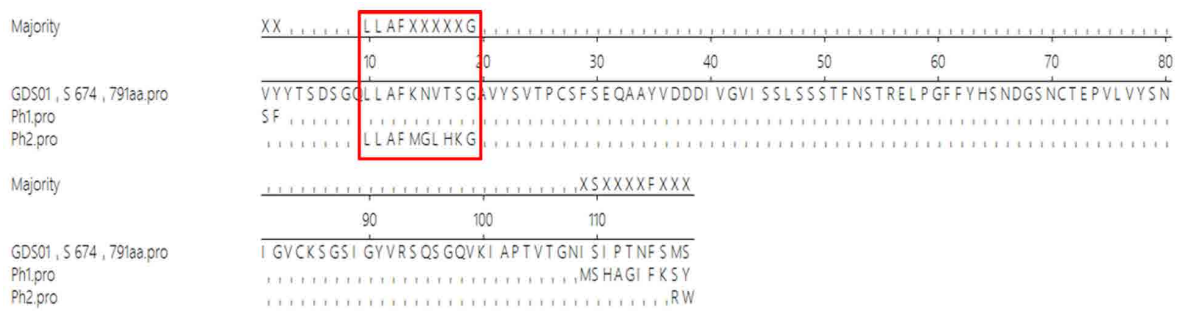

Fig. 4

Sequence alignment of the PEDV spike protein (674-791 aa)

The peptide motifs SFMSHAGIFKSY (represented by Ph1) and LLAFMGLHKGRW (represented by Ph2) were aligned with PEDV GDS01 (NCBI GenBank Acc. No. KM089829) using Lasergene MegAlign. 
Table 1 Prediction of the B cell epitopes of the PEDV spike protein (674-791 aa)

\begin{tabular}{cclc}
\hline No. & Start position & Sequence & End position \\
\hline 1 & 682 & SGQLLAFK & 690 \\
2 & 690 & TSGAVYSVTPCSFSEQAAYVDDDIVGVISSLSS & 722 \\
3 & 744 & CTEPVLVYSNIGVCKSGSIGYVRSQSGQVKIAP & 777 \\
\hline
\end{tabular}

The number $1 \mathrm{~B}$ cell epitope of the PEDV S protein, which encompasses the putative LLAF binding site of 3F10, is presented in bold.

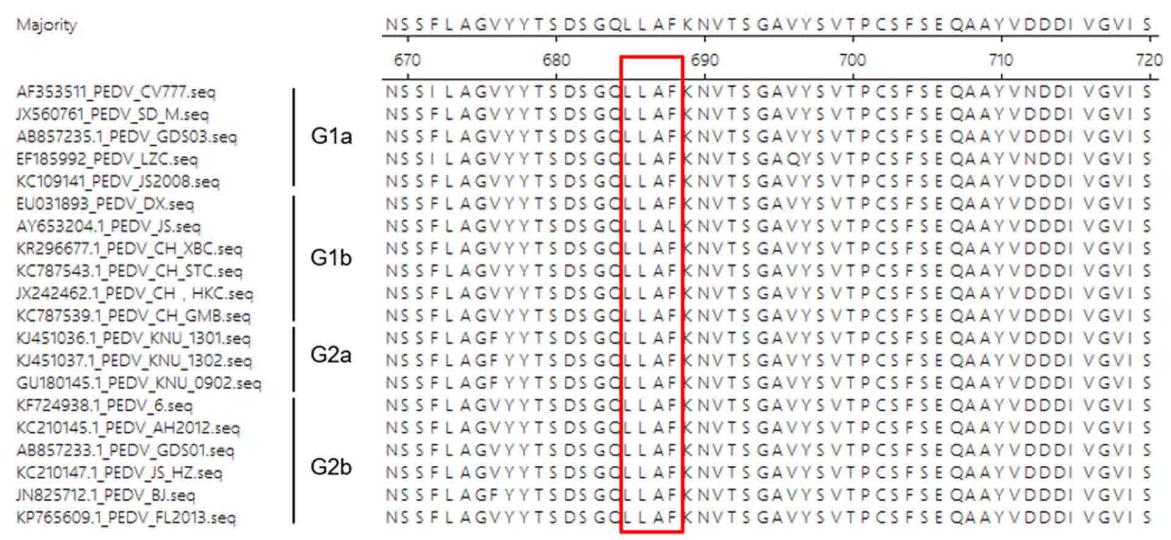

Fig. 6

Conservation of newly identified epitopes among 20 different representative strains of PEDV

The LLAF epitope motif is indicated by a red box. The GenBank Acc. Nos and strain names for each sequence are shown on the left side. The subgroups of the virus strains are shown to the right of the strain names. All sequences were aligned by Lasergene MegAlign.

thesized. The reactions of the synthesized peptides with 3F10 were tested by ELISA. The result shows that only ${ }_{680}$ SDSGQL $\mathrm{LAFKNV}_{691}$ had specific reaction with $3 \mathrm{~F} 10 \mathrm{mAb}$, while the peptide fragment that replaced LLAF and the unrelated

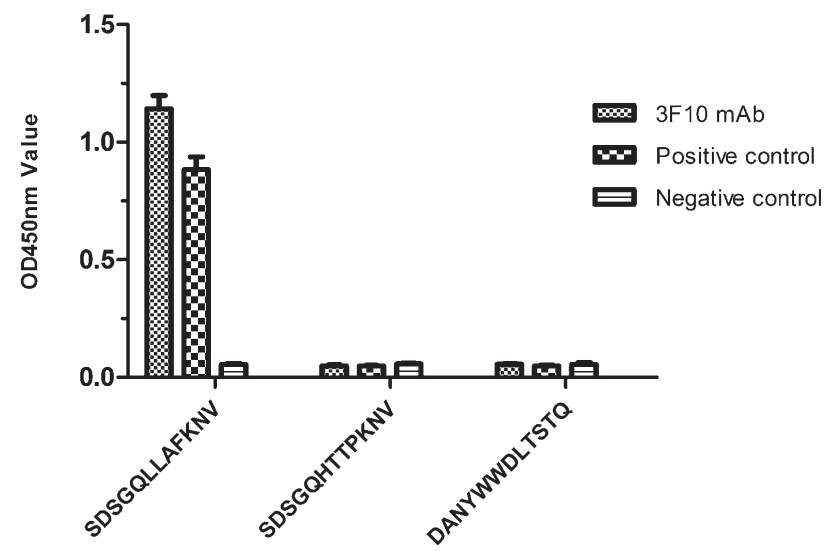

Fig. 5

Binding analysis of synthetic peptides and the $3 F 10 \mathrm{mAb}$ The OD450 values are shown on the y-axis. The sequences of the synthetic peptides are shown on the $\mathrm{x}$-axis. The positive control was detected by a positive polyclonal antibody. The negative control was detected by negative serum. polypeptide had no reaction with $3 \mathrm{~F} 10$, which indicates a highly significant difference (Fig. 5). This finding showed that LLAF were key aa for recognition by $3 \mathrm{~F} 10$.

\section{Conservation analysis and cross-reactions of $3 F 10$ antigenic epitopes}

The corresponding areas from 20 representative strains of PEDV were analyzed. The result showed that strains of all subtypes are completely homologous with the 3 F10 epitope region sequence, except the JS strain, in which aa 686 was mutated from $\mathrm{F}$ to $\mathrm{L}$, which indicates that the epitope is highly conserved (Fig. 6). To determine whether 3F10 can cross-react with a classic strain, GDS03 (belongig to the G1a subclass), which is kept in our laboratory, was selected. Vero cells incubated with the GDS03 virus were subjected to the IFA test, which showed that $3 \mathrm{~F} 10$ could specifically recognize GDS03. The positive polyclonal antibody and negative serum controls were valid (Fig. 7).

\section{Discussion}

Antigenic epitopes that contain approximately 5-15 aa have the function of stimulating immune cells to generate 

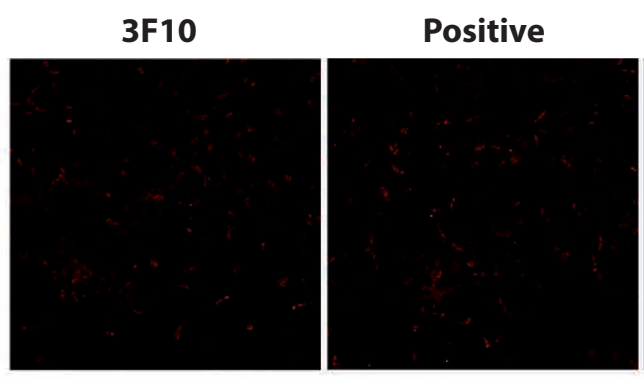

Negative

Fig. 7

3F10 cross-reaction with GDS03-infected cells was detected by IFA

A positive polyclonal antibody and negative serum were used as controls.

a specific antibody or a specific immunological reaction (Abbas, 2011). Antigenic epitopes can be divided into linear epitopes and conformational epitopes (Burton, 2002). However, most antigenic epitopes are conformational epitopes. Linear epitopes are several aa that are next to each other in the primary structure. Conformational epitopes refer to a discontinuous primary structure or spatial structure that is formed by some aa residues that are next to each other (Burton, 2002). Both linear epitopes and conformational epitopes combine with specific antibodies in a manner dependent on the key aa residues of the epitope; one aa mutation during the process of viral evolution can lead to a loss of or change in the antigenic epitope. Prokaryotic expression systems have the advantages of simple operation, rapid results, a high output of expressed recombinant protein, easy purification, low costs, etc. and are extensively used in gene engineering. However, the expressed proteins have low bioactivity and cannot be subjected to posttranslational modification for the folding of higher-order structures, such as glycosylation, phosphorylation, oligomerization, etc. In this study, 3F10 reacted with the SP7 protein expressed by prokaryotic cells, which indicates that it identified a linear epitope that is exposed on the surface of the virion.

Phage display biopanning technology has an important role in the identification of key antigen sites (Wang et al., 2017, 2018a,b), as it provides basic guidance for the prevention or diagnosis of target antigens and is extensively used for identifying linear epitopes. The screening process for target molecules was optimized as follows: 1. It successively reduces the coating quantity of the target molecule in each round; and 2. It gradually increases the concentration of Tween 20 in TBST to screen ligands of the $3 \mathrm{~F} 10 \mathrm{mAb}$ with high affinity and to reduce false-positive results caused by nonspecific adsorption. The time requirement of $4.5 \mathrm{~h}$ was strictly obeyed during the phage amplification process to avoid the generation of a phage with a strong preference caused by long-term amplification, which could have serious influence on the follow-up screening process. Two phages, $\mathrm{Ph} 1$ and $\mathrm{Ph} 2$, with high affinity peptide fragments
SFMSHAGIFKSY and LLAFMGLHKGRW were screened through five rounds of strict screening. The LLAF aa sequence in $\mathrm{Ph} 2$ was found to be highly homologous with aa 683-686 in the SP7 peptide fragment after sequence alignment with target peptide fragment SP7. The peptide fragments shown in Ph1 and Ph2 were virtual epitopes of 3F10, which may not represent its true epitopes in PEDV. S protein fragment pep ${ }_{\text {LLAF }}\left({ }_{680}\right.$ SDSGQLLAFKNV $\left._{691}\right)$, which included LLAF, S protein fragment pep ${ }_{\triangle \mathrm{LLAF}}\left({ }_{680}\right.$ SDSGQHTTPKNV $\left._{691}\right)$, which included a random replacement of LLAF, and the unrelated peptide fragment pep $_{\text {ran }}$ (DANYWWDLTSTQ) were manually synthesized. The results show that only pep $\mathrm{p}_{\mathrm{L}-}$ ${ }_{\text {LAF }}$ can react with $3 \mathrm{~F} 10$, which indicates that LLAF is a key aa sequence, by which 3F10 identifies the PEDV S protein epitope. To investigate the specificity and conservation of the above-identified antigenic epitope, different representative strains of PEDV were selected to analyze and compare the corresponding S protein aa sequence 683-686. The results show that the sequences of PEDV strains from different branches were highly conserved at the identified locus. IFA results show that 3F10 can identify both classic strains and variant strains, which is consistent with the high conservation of the antigenic epitope for the antibody. Positions with conserved epitopes are of great value in the development of epitope-based vaccines and are helpful for the establishment of highly sensitive and specific diagnostic methods (Oem et al., 2007).

Accumulating evidence proves that non-neutralizing antibodies play an important role in immunoprotection. Cooperation between non-neutralizing antibodies can neutralize the virus, and non-neutralizing antibodies can strengthen the neutralization by a neutralizing antibody (Howell et al., 2017; Mayr et al., 2017). Combining $m A b s$ targeting receptor binding domain (RBD) and non-RBD of middle east respiratory syndrome coronavirus can delay the neutralization escape (Wang et al., 2018c). Different immunodominant severe acute respiratory syndrome coronavirus epitopes can elicit disparate effects on infection in non-human primates (Sui et al., 2004; Wang et al., 2016b). However, the mechanisms 
have not been thoroughly elucidated. The determination of the antigenic epitope recognized by an antibody has great significance for understanding the structure and function of an antigen, the interactions between antibodies and other information related to immunoreactions, the development of a safe and effective vaccine strategy based on the epitope, and the development of diagnostic reagents based on the epitope. There are currently few studies of the antigenic epitopes of antibodies against the PEDV S protein. The identification of an antigenic epitope in the $S$ protein lays the foundation for research on the pathogenic mechanism and function of the $S$ protein and provides a basis for PEDV diagnosis and the development of an epitope vaccine.

Acknowledgments. This work was supported by the National Key Research and Development Program (grant No. 2016YFD0500101).

\section{References}

Abbas AK (2011): Basic Immunology - Functions and Disorders of the Immune System.

Burton DR (2002): Antibodies, viruses and vaccines. Nature 2, 706-713.

Cao L, Ge X, Gao Y, Zarlenga DS, Wang K, Li X, Qin Z, Yin X, Liu J, Ren X, Li G (2015): Putative Phage-display Epitopes of the Porcine Epidemic Diarrhea Virus S1 Protein and Their Anti-viral Activity. Virus Genes 51, 217-224. https://doi. org/10.1007/s11262-015-1234-5

Chang SH, Bae JL, Kang TJ, Kim J, Chung GH, Lim CW, Laude H, Yang MS, Jang YS (2002): Identification of the Epitope Region Capable of Inducing Neutralizing Antibodies against the Porcine Epidemic Diarrhea Virus. Mol. Cells 14, 295-299.

Cruz DJM, Kim C, Shin H (2006): Phage-displayed Peptides Having Antigenic Similarities with Porcine Epidemic Diarrhea Virus (PEDV) Neutralizing Epitopes. Virology 354, 28-34. https://doi.org/10.1016/j.virol.2006.04.027

Gong L, Lin Y, Qin J, Li Q, Xue C, Cao Y (2018): Neutralizing Antibodies against Porcine Epidemic Diarrhea Virus Block Virus Attachment and Internalization. Virol. J. 15, 133 https://doi.org/10.1186/s12985-018-1042-3

Hao J, Zhang Y, Fang S, Wen Z, Zhang X, Xue C, Cao Y (2017): Evaluation of Purified Recombinant Spike Fragments for Assessment of the Presence of Serum Neutralizing Antibodies against a Variant Vtrain of Porcine Epidemic Diarrhea virus. Virol. Sin. 32, 307-316. https://doi. org/10.1007/s12250-017-3969-8

Howell KA, Brannan JM, Bryan C, McNeal A, Davidson E, Turner HL, Vu H, Shulenin S, He S, Kuehne A, Herbert AS, Qiu X, Doranz BJ, Holtsberg FW, Ward AB, Dye JM, Aman MJ (2017): Cooperativity Enables Non-neutralizing Antibodies to Neutralize Ebolavirus. Cell Rep. 19, 413-424. https://doi.org/10.1016/j.celrep.2017.03.049

Jung K, Annamalai T, Lu Z, Saif LJ (2015): Comparative Pathogenesis of US Porcine Epidemic Diarrhea Virus (PEDV)
Strain PC21A in Conventional 9-day-old Nursing Piglets vs. 26-day-old Weaned Pigs. Vet. Microbiol. 178, 31-40. https://doi.org/10.1016/j.vetmic.2015.04.022

Kolaskar AS, Tongaonkar PC (1990): A Semi-empirical Method for Prediction of Antigenic Determinants on Protein Antigens. FEBS Lett. 276, 172-174. https://doi. org/10.1016/0014-5793(90)80535-Q

Lee C (2015): Porcine Epidemic Diarrhea Virus: An Emerging and Re-emerging Epizootic Swine Virus. Virol. J. 12, 193. https://doi.org/10.1186/s12985-015-0421-2

Li W, Van K, He Q, Rottier P, Bosch B (2016): Cellular Entry of the Porcine Epidemic Diarrhea Virus. Virus Res. 226, 117-127. https://doi.org/10.1016/j.virusres.2016.05.031

Mayr LM, Su B, Moog C (2017): Non-Neutralizing Antibodies Directed against HIV and Their Functions. Front. Immunol. 20, 87-95. https://doi.org/10.3389/fimmu.2017.01590

Mole B (2013): Deadly Pig Virus Slips through US Borders. Nature 499, 388. https://doi.org/10.1038/499388a

Oem JK, Chang BS, Joo HD, Yang MY, Kim GJ, Park JY, Ko YJ, Kim YJ, Park JH, Joo YS (2007): Development of an Epitope-blocking-enzyme-linked Immunosorbent Assay to Differentiate between Animals Infected with and Vaccinated against Foot-and-mouth Disease Virus. J. Virol. Methods 142, 174-181. https://doi.org/10.1016/j. jviromet.2007.01.025

Oh J, Lee KW, Choi HW, Lee C (2014): Immunogenicity and Protective Efficacy of Recombinant S1 Domain of the Porcine Epidemic Diarrhea Virus Spike Protein. Arch. Virol. 159, 2977-2987. https://doi.org/10.1007/s00705-014-2163-7

Oldham J (1972): Letter to the Editor. Pig Farming 22, 72-73. https://doi.org/10.1016/0094-114X(72)90046-8

Song D, Park B (2012): Porcine Epidemic Diarrhoea Virus: a Comprehensive Review of Molecular Epidemiology, Diagnosis, and Vaccines. Virus Genes 44, 167-175. https:// doi.org/10.1007/s11262-012-0713-1

Sun D, Feng L, Shi H, Chen J, Cui X, Chen H, Liu S, Tong Y, Wang Y, Tong G (2008): Identification of Two Novel B Cell Epitopes on Porcine Epidemic Diarrhea Virus Spike Protein. Vet. Microbiol. 131, 73-81. https://doi.org/10.1016/j. vetmic.2008.02.022

Sun DB, Feng L, Shi HY, Chen JF, Liu SW, Chen HY, Wang YF (2007): Spike Protein Region (aa 636-789) of Porcine Epidemic Diarrhea Virus is Essential for Induction of Neutralizing Antibodies. Acta Virol. 51, 149-156.

Sui JH, Li WH, Murakami A, Tamin A, Mattews LJ, Wong SK, Moore MJ, Tallarico ASC, Olurinde M, Choe H, Anderson LJ, Bellini WJ, Farzan M, Marasco WA (2004): Potent Neutralization of Severe Acute Respiratory Syndrome (SARS) Coronavirus by a Human mAb to S1 Protein That Blocks Receptor Association. Proc. Natl. Acad. Sci. USA 101, 2536-2541. https://doi.org/10.1073/ pnas.0307140101

Wang D, Fang L, Xiao S (2016a): Porcine Epidemic Diarrhea in China. Virus Res. 226, 7-13. https://doi.org/10.1016/j. virusres.2016.05.026

Wang H, Zhang W, Gu H, Chen W, Zeng M (2017): Identification and Characterization of Two Linear Epitope Motifs in 
Hepatitis E Virus ORF2 Protein. PLoS One 12, 9-25. https://doi.org/10.1371/journal.pone.0184947

Wang J, Song J, Zhou S, Fu Y, Bailey JA, Shen C (2018a): Screening and Identification of RhD Antigen Mimic Epitopes from a Phage Display Random Peptide Library for the Serodiagnosis of Haemolytic Disease of the Foetus and Newborn. Blood Transfus. 6, 1-7.

Wang LS, Shi W, Chappell JD, Joyce G, Zhang Y, Kanekiyo M, Becker MM, Doremalen NV, Fischer R, Wang N, Corbett KS, Choe M, Mason RD, Galen JGV, Zhou T, Saunders KO, Tatti KM, Haynes LM, Kwong PD, Modjarrad K, Kong WP, Mclellan JS, Denison MR, Munster VJ, Mascola JR, Graham BS (2018c): Importance of Neutralizing Monoclonal Antibodies Targeting Multiple Antigenic Sites on the Middle East Respiratory Syndrome
Coronavirus Spike Glycoprotein To Avoid Neutralization Escape. J. Virol. 92, e02002-17. https://doi.org/10.1128/ JVI.02002-17

Wang M, Wei Y, Yu W, Wang L, Zhai L, Li X, Wang X, Zhang H, Feng Z, Yu L, Yu Y, Ma J, Cui Y (2018b): Identification of a Conserved Linear B-cell Epitope in the Staphylococcus Aureus Gap C protein. Microb. Pathog. 118, 39-47. https://doi.org/10.1016/j.micpath.2018.03.007

Wang QD, Zhang LF, Kuwahara K, Li L, Liu ZJ, Li TS, Zhu H, Liu JN, Xu YF, Xie J, Morioka H, Sakaguchi N, Qin C, Liu G (2016b): Immunodominant SARS Coronavirus Epitopes in Humans Elicited both Enhancing and Neutralizing Effects on Infection in Non-human Primates. ACS Infect. Dis. 2, 361-376. https://doi.org/10.1021/ acsinfecdis.6b00006 